\title{
AN N-FaCtOR GaUSSIAN Model of Oil Futures \\ Prices
}

\section{GONZALO CORTAZAR* LORENZO NARANJO}

\begin{abstract}
This article studies the ability of an $\mathrm{N}$-factor Gaussian model to explain the stochastic behavior of oil futures prices when estimated with the use of all available price information, as opposed to traditional approaches of aggregating data for a set of maturities. A Kalman filter estimation procedure that allows for a time-dependent number of daily observations is used to calibrate the model. When applied to all daily oil futures price transactions from 1992 to 2001, the model performs very well, requiring at least three factors to explain the term structure of futures prices, but four factors to fit the volatility term structure. The model also performs very well for daily copper futures transactions from 1992 to 2001 and for out-of-sample daily oil futures transactions from 2002 to 2004. (C) 2006 Wiley Periodicals, Inc. Jrl Fut Mark 26:243-268, 2006
\end{abstract}

\footnotetext{
The authors thank the researchers of the FINlabUC-Laboratorio de Investigación Avanzada en Finanzas-Pontificia Universidad Católica de Chile-for helpful discussions and excellent research assistance. Most of the work was completed while Lorenzo Naranjo was at the FINlabUC at the Pontificia Universidad Católica de Chile. They also acknowledge the financial support of FONDECYT (Grant No. 1040608), FONDEF (Grant No. D03I1039), and Fundacion COPECUniversidad Católica (Grant No. PC00021).

${ }^{*}$ Correspondence author, Departamento de Ingeniería Industrial y de Sistemas, Pontificia Universidad Católica de Chile, Vicuña Mackenna 4860, Santiago, Chile; e-mail: gcortaza@ing.puc.cl

Received September 2004; Accepted July 2005
}

- Gonzalo Cortazar is a Professor at the Departamento de Ingeniería Industrial y de Sistemas, Escuela de Ingeniería, Pontificia Universidad Católica de Chile in Santiago, Chile.

- Lorenzo Naranjo is a Ph.D. candidate at the Stern School of Business at New York University in New York. 


\section{INTRODUCTION}

The valuation and hedging of commodity contingent claims has received a great amount of attention by both academics and practitioners, and has become an important area of financial economics. Inextricably interwoven with this issue is the modeling and estimation of the stochastic behavior of commodity prices. The practical implication of having better models and estimation methodologies is that commodity producers and consumers, and also financial intermediaries, may implement sound investment and risk-management strategies with vast economic implications. On the contrary, the application of naïve models can lead to unreliable results, which may include heavy financial losses to corporations (Culp \& Miller, 1994).

Among commodities traded in financial markets, oil is one of the most important, and has been studied in the literature extensively. Its relevance induces innovations in financial markets, generating new oil contingent claims that should be used in the estimation of the stochastic behavior of oil prices.

One important source of information for the study of oil prices is the futures market. Oil futures markets have included in recent years new futures contracts with longer maturities up to 7 years. When new contracts are introduced there is no historical information. In addition, not all futures contracts trade every day. If a complete data set of prices is to be used, some prices need to be discarded or aggregated, with great information loss. Thus, it would be desirable that the estimation procedure uses all price information available.

Oil prices are very volatile, have a high degree of mean reversion (Bessembinder, Coughenour, Seguin, \& Smoller, 1995), and exhibit complex dynamics. Thus, it is important to analyze the number of risk factors required to model this stochastic behavior (Cortazar \& Schwartz, 1994).

Several models of the stochastic process followed by commodity prices have been proposed in the literature. They differ in how they specify spot price innovations and how they model the cost of carry. The cost of carry represents the storage cost plus the interest paid to finance the asset minus the net benefit that accrues to the asset holder, if any. In the commodities literature, the benefit received by the commodity owner, but not by the futures contract owner, is called the convenience yield (Brennan, 1958, 1991; Deaton \& Laroque, 1992; Gibson \& Schwartz, 1990; Routledge, Seppi, \& Spatt, 2000; Working, 1949), which is commonly represented as a dividend yield. 
Early models of commodity prices assume a one-factor geometric Brownian motion for the spot price with a constant interest rate and convenience yield, which implies a constant cost of carry (Brennan \& Schwartz, 1985). Even though this widely used and simple model has the advantage of being very tractable, it has some undesirable properties like exhibiting a constant volatility term structure of futures price returns. Empirical evidence suggests, however, that the volatility term structure of futures prices is a decreasing function of maturity (Bessembinder, Coughenour, Seguin, \& Smoller, 1996), which may be explained by the existence of mean reversion in commodity prices (Bessembinder et al., 1995).

To address this issue, several authors have proposed different onefactor models that take into account mean reversion in commodity prices (Laughton \& Jacoby, 1993, 1995; Ross, 1997; Schwartz, 1997). However, an empirical implication of all models that consider a single source of uncertainty is that futures prices for different maturities should be perfectly correlated, which defies existing evidence.

To account for a more realistic model of commodity prices, two- and three-factor models have been proposed ${ }^{1}$ (Cortazar \& Schwartz, 2003; Gibson \& Schwartz, 1990; Hilliard \& Reis, 1998; Schwartz, 1997; Schwartz \& Smith, 2000). The advantage of using more factors in modeling the spot price process and the cost of carry is that a better fit to observed futures prices may be obtained. This goodness of fit can generally be observed not only in terms of mean-squared errors, but also by comparing empirical and model-implied volatility term structures, which is critical for valuing option-like contingent claims and also for riskmanagement applications.

In addition to defining the commodity price model, a methodology to obtain parameter estimates must be chosen. For Gaussian models such as the one presented in this article, a closed-form formula of the probability distribution of futures prices is known, and parameters may be obtained by maximizing their likelihood function. Therefore, consistent estimates of model parameters are obtained with their respective estimation errors.

Some difficulties must be addressed, however, to successfully apply these models to commodity markets. For example, most multifactor models are based on nonobservable state variables that must be estimated from observed prices. Thus, in addition to calibrating model parameters,

${ }^{1}$ A different approach for modeling the spot price of a commodity is based on the Heath, Jarrow, and Morton (1992) no-arbitrage model (Cortazar \& Schwartz, 1994; Miltersen \& Schwartz, 1998). 
which are assumed constant for each data set, it is necessary to estimate state variables for each date.

When state variables and futures prices are related by a closed-form formula, it is possible to estimate the unobserved state variables by inverting the pricing formula (Chen \& Scott, 1993; Duffie \& Singleton, 1997; Pearson \& Sun, 1994). In this case, it is assumed that futures prices are observed without measurement error. However, for any given date the number of available prices is generally higher than the number of state variables that need to be estimated. Therefore, it must be assumed that observed prices have some degree of measurement error, which has to be assigned across the different contracts. Moreover, it may be desirable to include as many observed futures prices as possible in the estimation process of the state variables.

One of the most successful econometric procedures that takes into account the above issues is the Kalman filter, a widely used estimation methodology that can handle multifactor models with nonobservable state variables and measurement errors. In addition, it is capable of using a large price panel in the estimation process, avoiding the necessity of making an arbitrary selection of contracts to include in the estimation. The Kalman filter has been used in finance to estimate state variables of commodity price models by Schwartz (1997), Schwartz and Smith (2000), Manoliu and Tompaidis (2002), and Sørensen (2002), among others.

Traditional implementations of the Kalman filter normally assume a complete panel data set. This implies that for all given dates in the estimation sample, prices for the same set of contracts (with the same maturities) must be observed. This is not normally the case, because financial markets have innovations, and new contracts with longer maturities are frequently introduced. Traditional applications of the Kalman filter typically address this missing-data problem by aggregating or discarding data, with the consequent loss of information.

The missing-data problem may be so relevant that some authors have chosen not to use the Kalman filter, but to propose an alternative procedure to handle cases where the panel data are incomplete. Cortazar and Schwartz (2003) propose a very simple estimation procedure and apply it to an incomplete panel of oil futures prices. The methodology, however, does not make an optimal use of prices in the estimation of state variables (as opposed to the Kalman filter), and is unable to obtain parameter estimation errors.

An alternative procedure used in this article is to modify the traditional application of the Kalman filter to address incomplete panel-data 
conditions. Sørensen (2002) uses this procedure for a seasonal price model, and Cortazar, Schwartz, and Naranjo (2003) use it for estimating the term structure of interest rates in an emerging market with lowfrequency transactions. However, this approach has not received much attention in the literature.

This article studies the ability of an N-factor Gaussian model to explain the stochastic behavior of oil futures prices when estimated with the use of all price information available, as opposed to traditional approaches of aggregating data for a set of maturities. A Kalman filter estimation procedure that allows for a time-dependent number of daily observations is used to calibrate the model. When applied to all daily oil futures price transactions from 1992 to 2001, the model performs very well, requiring at least three factors to explain the term structure of futures prices, but four factors to fit the volatility term structure.

The organization of the article is as follows. The next section explains the $N$-factor Gaussian model for the spot price of oil. The Kalman filter methodology is then presented in an incomplete panel-data setting. Estimation results for oil futures prices are presented, and a conclusion is provided.

\section{OIL PRICE MODEL AND FUTURES VALUATION}

In this section an $N$-factor Gaussian model for the spot price of a commodity is presented, as well as its relation with other models commonly found in the commodities literature. In addition, valuation formulas for futures contracts and the theoretical volatility term structure of futures returns are obtained.

\section{The Model}

The $N$-factor model presented in this article generalizes existing twoand three-factor models commonly found in the literature (Cortazar \& Schwartz, 2003; Gibson \& Schwartz, 1990; Schwartz, 1997; Schwartz \& Smith, 2000) to an $N$-factor setting. The model is based on the $A_{0}(N)$ canonical representation of Dai and Singleton (2000) for interest rates, which can be traced back to Vasicek (1977) and Langetieg (1980). However, in contrast to the interest-rates literature, which usually assumes a stationary process for the underlying spot rate, the Gaussian model for the spot price presented in this article is nonstationary, as it is usually assumed in the commodities literature. 
Even though one-factor models may be able to explain a sizable fraction of the total price variance, these models tend to fit observed futures prices and the term structure of the volatility of futures returns rather poorly. The optimal number of factors that should be specified in a model depends on the stochastic behavior of the term structure of the specific commodity that is being modeled (Cortazar \& Schwartz, 1994), and on the complexity that the modeler is willing to accept.

The $\mathrm{N}$-factor model presented in the following extends existing models of commodity prices to an arbitrary number of factors while providing simple analytic valuation formulas for futures prices. This renders the model tractable and easy to implement and calibrate. Moreover, the model is Gaussian, which allows the use of the Kalman filter to estimate unobserved state variables and the use of maximumlikelihood techniques to calibrate model parameters. However, previous commodity literature has only focused in using one-, two-, and three-factor models, without extending its use to a general $\mathrm{N}$-factor setting.

In this model, the spot price process of the commodity can be described as

$$
\log S_{t}=\mathbf{1}^{\prime} \mathbf{x}_{t}+\mu t
$$

where $\mathbf{x}_{t}$ is a $n \times 1$ vector of state variables and $\mu$, the long-term growth rate, is a constant. The vector of state variables $\mathbf{x}_{t}$ follows the process

$$
d \mathbf{x}_{t}=-\mathbf{K} \mathbf{x}_{t} d t+\mathbf{\Sigma} d \mathbf{w}_{t}
$$

where

$$
\mathbf{K}=\left(\begin{array}{cccc}
0 & 0 & \cdots & 0 \\
0 & \kappa_{2} & \cdots & 0 \\
\vdots & \vdots & \ddots & \vdots \\
0 & 0 & \cdots & \kappa_{n}
\end{array}\right) \quad \text { and } \quad \boldsymbol{\Sigma}=\left(\begin{array}{cccc}
\sigma_{1} & 0 & \cdots & 0 \\
0 & \sigma_{2} & \cdots & 0 \\
\vdots & \vdots & \ddots & \vdots \\
0 & 0 & \cdots & \sigma_{n}
\end{array}\right)
$$

are $n \times n$ diagonal matrices with entries that are positive constants. Also, $d \mathbf{w}_{t}$ is a $n \times 1$ vector of correlated Brownian motion increments such that $\left(d \mathbf{w}_{t}\right)^{\prime}\left(d \mathbf{w}_{t}\right)=\boldsymbol{\Omega} d t$, where the $(i, j)$ element of $\boldsymbol{\Omega}$ is $\rho_{i j} \in[1,-1]$, the instantaneous correlation between state variables $i$ and $j$.

This model specification implies that the state variables have a multivariate Normal distribution. The first state variable follows a random walk, inducing a unit root in the spot price process. Each of the other state variables reverts to zero at a mean reversion rate given by $k_{i}$. In 
order to compare the present model to traditional models found in the commodities literature, $\kappa_{1}$ has been exogenously set to zero. ${ }^{2}$

By assuming a constant risk premium ${ }^{3} \boldsymbol{\lambda}$, the risk-adjusted process for the vector of state variables is

$$
d \mathbf{x}_{t}=-\left(\boldsymbol{\lambda}+\mathbf{K} \mathbf{x}_{t}\right) d t+\boldsymbol{\Sigma} d \mathbf{w}_{t}^{*}
$$

where $\boldsymbol{\lambda}$ is a $n \times 1$ vector of real constants.

Instead of modeling the risk-free interest rate and the convenience yield independently (Gibson \& Schwartz, 1990), this article models the cost of carry $c_{t}$ (Schwartz \& Smith, 2000), defined as the difference between the instantaneous risk-free interest rate $r_{t}$ and the convenience yield $\delta_{t}$.

\section{Affine Transformations of the Model}

This subsection shows how to rewrite a model through an affine transformation, and this procedure is later applied to the Gibson and Schwartz (1990) model to show that this is a particular case of the $\mathrm{N}$-factor model presented in this article.

Consider the following model:

$$
\begin{gathered}
\log S_{t}=\overline{\mathbf{h}}^{\prime} \boldsymbol{\zeta}_{t}+\bar{\mu}(t) \\
d \zeta_{t}=\left(-\overline{\mathbf{K}} \boldsymbol{\zeta}_{t}+\overline{\boldsymbol{\beta}}\right) d t+\overline{\boldsymbol{\Sigma}} d \overline{\mathbf{w}}_{t}
\end{gathered}
$$

where $\zeta_{t}$ is a vector of state variables, $d \overline{\mathbf{w}}_{t} d \overline{\mathbf{w}}_{t}^{\prime}=\overline{\boldsymbol{\Omega}} d t, \bar{\mu}(t)$ is a scalar function, $\overline{\mathbf{h}}$ and $\overline{\boldsymbol{\beta}}$ are vectors, and matrices $\overline{\mathbf{K}}$ and $\overline{\boldsymbol{\Sigma}}$ need not be diagonal.

Then, the following affine transformation $\mathbf{T}\left(\boldsymbol{\zeta}_{t}\right)=\mathbf{L} \boldsymbol{\zeta}_{t}+\boldsymbol{\varphi}(t)$ may be applied to the original state vector $\zeta_{t}$ to obtain a new state vector $\mathbf{x}_{t}=\mathbf{T}\left(\boldsymbol{\zeta}_{t}\right)$. If the matrix $\mathbf{L}$ is invertible, then there exists a one-to-one correspondence between the state variables of the two models. The new model is

$$
\begin{gathered}
\log S_{t}=\mathbf{h}^{\prime} \mathbf{x}_{t}+\mu(t) \\
d \mathbf{x}_{t}=\left(-\mathbf{K} \mathbf{x}_{t}+\boldsymbol{\beta}\right) d t+\boldsymbol{\Sigma} d \mathbf{w}_{t}
\end{gathered}
$$

\footnotetext{
${ }^{2}$ Obviously, this assumption could easily be relaxed in order to study stationary models of commodity prices. Actually, when the model was estimated with this assumption relaxed, no significant differences were found. Also, the model performs well for other commodities, as will be shown later when calibrated with copper futures.

${ }^{3}$ It is assumed for simplicity that the risk premium is constant. However, this could be extended to any linear function of the state variables to reflect a possible correlation between spot prices, convenience yields, and interest rates (Casassus \& Collin-Dufresne, 2005).
} 
where $\mathbf{h}^{\prime}=\overline{\mathbf{h}}^{\prime} \mathbf{L}^{-1}, \mu(t)=\bar{\mu}(t)-\mathbf{h}^{\prime} \boldsymbol{\varphi}(t), \mathbf{K}=\mathbf{L} \overline{\mathbf{K}} \mathbf{L}^{-1}, \boldsymbol{\beta}=\mathbf{K} \boldsymbol{\varphi}(t)+\mathbf{L} \overline{\boldsymbol{\beta}}$, $d \mathbf{w}_{t} d \mathbf{w}_{t}^{\prime}=\boldsymbol{\Omega} d t, \boldsymbol{\Sigma} \boldsymbol{\Omega} \mathbf{\Sigma}=\mathbf{L} \overline{\boldsymbol{\Sigma}} \overline{\boldsymbol{\Omega}} \overline{\mathbf{\Sigma}} \mathbf{L}^{\prime}$ and $\mathbf{\Sigma}=\mathbf{L} \overline{\boldsymbol{\Sigma}}$.

From the analysis of Dai and Singleton (2000) it follows that there exists an affine transformation $\mathbf{T}(\cdot)$ that rewrites any model to another one with the maximum number of parameters that can be econometrically identified. In particular, if the reversion matrix $\mathbf{K}$ is restricted to have termwise different eigenvalues, then an arbitrary $N$-factor model can always be transformed to a model like the one presented in Equations (1) and (2). ${ }^{4}$

For example, consider the Gibson and Schwartz (1990) model:

$$
\begin{gathered}
\log S_{t}=\mathbf{h}^{\prime} \boldsymbol{\zeta}_{t} \\
d \zeta_{t}=\left(-\overline{\mathbf{K}} \boldsymbol{\zeta}_{t}+\boldsymbol{\beta}\right) d t+\overline{\boldsymbol{\Sigma}} d \overline{\mathbf{w}}_{t}
\end{gathered}
$$

where $\mathbf{h}^{\prime}=\left(\begin{array}{ll}1 & 0\end{array}\right), \overline{\mathbf{K}}=\left(\begin{array}{cc}0 & 0 \\ 0 & \kappa\end{array}\right), \boldsymbol{\beta}=\left(\begin{array}{c}\mu-1 / 2 \sigma_{1}^{2} \\ \kappa \alpha\end{array}\right), \bar{\Sigma}=\left(\begin{array}{cc}\bar{\sigma}_{1} & 0 \\ 0 & \bar{\sigma}_{2}\end{array}\right)$ and $d \overline{\mathbf{w}}_{t} d \overline{\mathbf{w}}_{t}^{\prime}=\overline{\mathbf{\Omega}} d t=\left(\begin{array}{cc}1 & \bar{\rho} \\ \bar{\rho} & 1\end{array}\right) d t$

To obtain the relationship between the two models, the following affine transformation is applied over the original state variable vector $\boldsymbol{\zeta}_{t}$ :

$$
\mathbf{x}_{t}=\mathbf{L} \zeta_{t}+\varphi
$$

where $\mathbf{L}=\left(\begin{array}{cc}1 & -1 / \kappa \\ 0 & 1 / \kappa\end{array}\right)$ and $\boldsymbol{\varphi}=\left(\begin{array}{c}\left(\mu-1 / 2 \sigma_{1}^{2}-\alpha\right) t-\alpha / \kappa \\ \alpha / \kappa\end{array}\right)$.

The new vector $\mathbf{x}_{t}$ corresponds to the state variables in the new model. This transformation is invertible, and therefore it establishes a one-to-one correspondence between the state variables of the two models, obtaining

$$
\begin{gathered}
\log S_{t}=\mathbf{1}^{\prime} \mathbf{x}_{t}+\left(\mu-\frac{1}{2} \sigma_{1}^{2}-\alpha\right) t \\
d \mathbf{x}_{t}=-\mathbf{K} \mathbf{x}_{t} d t+\boldsymbol{\Sigma} d \mathbf{w}_{t}
\end{gathered}
$$

where $\mathbf{K}=\left(\begin{array}{cc}0 & 0 \\ 0 & \kappa\end{array}\right), \mathbf{\Sigma}=\left(\begin{array}{cc}\sigma_{1} & 0 \\ 0 & \sigma_{2}\end{array}\right)$ and $d \mathbf{w}_{t} d \mathbf{w}_{t}^{\prime}=\boldsymbol{\Omega} d t=\left(\begin{array}{cc}1 & \rho_{21} \\ \rho_{21} & 1\end{array}\right) d t$.

\footnotetext{
${ }^{4}$ The reversion matrix is assumed to have termwise different eigenvalues to obtain simpler valuation formulas for futures contracts.
} 
The existing relationship between the variance-covariance parameters of the two models is given by $\mathbf{\Sigma} \boldsymbol{\Omega} \mathbf{\Sigma}=\mathbf{L} \mathbf{\Sigma} \mathbf{\Omega} \mathbf{\Sigma} \mathbf{L}^{\prime}$. Assuming a constant risk premium $\lambda_{i}$ for each state variable, the risk-adjusted process of the Gibson and Schwartz (1990) model is

$$
d \mathbf{x}_{t}=\left(-\overline{\mathbf{K}} \zeta_{t}+\boldsymbol{\beta}-\overline{\boldsymbol{\lambda}}\right) d t+\overline{\mathbf{\Sigma}} d \overline{\mathbf{w}}_{t}
$$

Under the equivalent martingale measure the drift of the spot price of a commodity must be equal to the difference between the instantaneous interest rate $r$, which is assumed constant by Gibson and Schwartz (1990), and its instantaneous convenience yield, so the following relation must hold:

$$
\mu-\lambda=r
$$

The risk-adjusted process of the new model is:

$$
d \mathbf{x}_{t}=\left(-\mathbf{K} \mathbf{x}_{t}-\boldsymbol{\lambda}\right) d t+\boldsymbol{\Sigma} d \mathbf{w}_{t}
$$

Then, it can be shown that the relationship between the risk premiums of the two models is $\boldsymbol{\lambda}=\mathbf{L} \overline{\boldsymbol{\lambda}}$.

Under this new representation, it follows from Equations (11) and (14) that it is not possible to estimate $\mu, \alpha$, and $\lambda$ independently. One of the three parameters, or a linear combination of them, must be exogenously specified. In the article, Gibson and Schwartz (1990) estimate from government bond data the instantaneous risk-free interest rate $r=\mu-\lambda$.

\section{Futures Prices}

The price of a futures contract at time $t$ and maturing at $T$ can then be found as the expected value of the spot price under the risk-neutral measure (Cox, Ingersoll, \& Ross, 1981):

$$
F\left(\mathbf{x}_{t}, t, T\right)=\mathrm{E}_{t}^{Q}\left(S_{T}\right)
$$

As shown in the Appendix, the expected value in Equation (16) can be computed as

$$
\begin{aligned}
F\left(\mathbf{x}_{t}, t, T\right)= & \exp \left(x_{1}(t)+\sum_{i=2}^{N} \mathrm{e}^{-\kappa_{i}(T-t)} x_{i}(t)+\mu t+\left(\mu-\lambda_{1}+\frac{1}{2} \sigma_{1}^{2}\right)(T-t)\right. \\
& \left.-\sum_{i=2}^{N} \frac{1-\mathrm{e}^{-\kappa_{i}(T-t)}}{\kappa_{i}} \lambda_{i}+\frac{1}{2} \sum_{i \cdot j \neq 1} \sigma_{i} \sigma_{j} \rho_{i j} \frac{1-\mathrm{e}^{-\left(\kappa_{i}+\kappa_{j}\right)(T-t)}}{\kappa_{i}+\kappa_{j}}\right)
\end{aligned}
$$


One important advantage of this model is its tractability, with explicit futures price formulas even for an arbitrary number of factors. In addition, the logarithm of the futures price is a linear function of state variables, which is useful when estimating the model with a Kalman-filter-based procedure. Because the state variables have a multivariate normal distribution, any linear combination of state variables will also distribute normal, allowing maximum-likelihood techniques to be used.

Finally, the model volatility term structure of futures returns can be obtained from Equations (2) and (17):

$$
\sigma_{F}^{2}(\tau)=\sum_{i=1}^{n} \sum_{j=1}^{n} \sigma_{i} \sigma_{j} \rho_{i j} e^{-\left(\kappa_{i}+\kappa_{j}\right) \tau}
$$

Given that $\kappa_{1}=0$, as the maturity of a futures contract grows, the volatility of futures returns converges to a constant given by $\sigma_{1}$, which is the volatility of the first state variable.

\section{ESTIMATION METHODOLOGY}

The Kalman filter is an estimation methodology that recursively calculates optimal estimates of unobservable state variables with the use of all past information. Consistent parameter estimates can be obtained by maximizing the likelihood function of error innovations. In the finance literature, the Kalman filter has been used to estimate and implement stochastic models of commodities (Schwartz, 1997; Schwartz \& Smith, 2000; Sørensen, 2002), interest rates (Babbs \& Nowman, 1999; Cortazar, Schwartz, \& Naranjo, 2003; de Jong, 2000; de Jong \& Santa-Clara, 1999; Duan \& Simonato, 1999; Geyer \& Pichler, 1999; Lund, 1994, 1997), and other relevant economic variables (Pennacchi, 1991). Although widely used in a complete panel-data setting, most literature has not focused on using the Kalman filter where there are missing observations in the panel, a common feature in many commodity futures markets.

One of the characteristics of the Kalman filter is that state variables estimates are obtained with the use of a rich information set that includes past information and not only current prices. Moreover, it can allow for measurement errors in observable variables that may be induced by market imperfections or by the inability of a model with a restricted number of factors to explain the whole structure of contemporaneous observations.

The Kalman filter may be applied to dynamic models that are in a state-space representation. The measurement equation relates a vector of observable variables $\mathbf{z}_{t}$ with a vector of state variables $\mathbf{x}_{t}$ :

$$
\mathbf{z}_{t}=\mathbf{H}_{t} \mathbf{x}_{t}+\mathbf{d}_{t}+\mathbf{v}_{t} \quad \mathbf{v}_{t} \sim \mathbf{N}\left(\mathbf{0}, \mathbf{R}_{t}\right)
$$


where $\mathbf{z}_{t}$ is a $m_{t} \times 1$ vector, $\mathbf{H}_{t}$ is a $m_{t} \times n$ matrix, $\mathbf{x}_{t}$ is a $n \times 1$ vector, $\mathbf{d}_{t}$ is a $m_{t} \times 1$ vector, $\mathbf{v}_{t}$ is a $m_{t} \times 1$ vector of serially uncorrelated Gaussian disturbances with mean $\mathbf{0}$ and covariance matrix $\mathbf{R}_{t}$ of dimension $m_{t} \times m_{t}$, and $m_{t}$ is the number of observations available at time $t$.

Measurement Equation (19) assumes the existence of a linear relation between observed variables and state variables. As noted above, in this model the logarithm of futures prices is a linear function of state variables. Nevertheless, the Kalman filter could be modified (Harvey, 1989) to allow for nonlinear measurement equations, as would be the case if, for example, commodity option prices alone, or in combination with futures prices, were used as observations.

The transition equation describes the stochastic process followed by the state variables:

$$
\mathbf{x}_{t}=\mathbf{A}_{t} \mathbf{x}_{t-1}+\mathbf{c}_{t}+\boldsymbol{\varepsilon}_{t} \quad \boldsymbol{\varepsilon}_{t} \sim N\left(\mathbf{0}, \mathbf{Q}_{t}\right)
$$

where $\mathrm{A}_{t}$ is an $n \times n$ matrix, $\mathbf{c}_{t}$ is an $n \times 1$ vector, and $\boldsymbol{\varepsilon}_{t}$ is an $n \times 1$ vector of serially uncorrelated Gaussian disturbances with mean $\mathbf{0}$ and covariance matrix. Given this state-space representation, the Kalman filter calculates optimal estimates $\hat{\mathbf{x}}_{t}$ of state variables and the variancecovariance matrix $\mathbf{P}_{t}=\mathrm{E}\left(\mathbf{x}_{t}-\hat{\mathbf{x}}_{t}\right)\left(\mathbf{x}_{t}-\hat{\mathbf{x}}_{t}\right)^{T}$.

The Kalman filter then works recursively, using the previous estimations. First, the one-step-ahead prediction at time $t$ of the state variables $\hat{\mathbf{x}}_{t \mid t-1}$ and its error variance-covariance matrix $\mathbf{P}_{t \mid t-1}$ given all information up to time $t-1$ are computed:

$$
\begin{gathered}
\hat{\mathbf{x}}_{t \mid t-1}=\mathbf{A}_{t} \hat{\mathbf{x}}_{t-1}+\mathbf{c}_{t} \\
\mathbf{P}_{t \mid t-1}=\mathbf{A}_{t} \mathbf{P}_{t-1} \mathbf{A}_{t}^{\prime}+\mathbf{Q}_{t}
\end{gathered}
$$

This allows for the calculation of one-step-ahead prediction of observed variables:

$$
\hat{\mathbf{z}}_{t \mid t-1}=\mathbf{H}_{t} \hat{\mathbf{x}}_{t \mid t-1}+\mathbf{d}_{t}
$$

These calculations only consider the dynamic properties of state variables and are not affected by the dimension of the vector of observable variables. The prediction error or innovation $\boldsymbol{v}_{t}$ and its associated variance-covariance matrix $\mathbf{F}_{t}$ are:

$$
\begin{gathered}
\boldsymbol{v}_{t}=\mathbf{z}_{t}-\hat{\mathbf{z}}_{t \mid t-1} \\
\mathbf{F}_{t}=\mathbf{H}_{t} \mathbf{P}_{t \mid t-1} \mathbf{H}_{t}^{\prime}+\mathbf{R}_{t}
\end{gathered}
$$


When futures contracts are used as observations, the measurement equation gives the futures price as a function of state variables and its maturity, allowing all observed prices to be used in the estimation process. With the use of Equation (17), the $m_{t}$ row vectors of the matrix $\mathbf{H}_{t}$ and the elements of the vector $\mathbf{d}_{t}$ can be computed.

In addition, the covariance matrix of measurement error $\mathbf{R}_{t}$ must be parametrized. For this purpose, the Babbs and Nowman (1999) approach is followed, where it is assumed that all measurement errors are independent and have the same variance, $\xi^{2}$, inducing a diagonal covariance matrix $\mathbf{R}_{t}$. Although this assumption could be relaxed, there is a tradeoff between the accuracy and the complexity of the model in terms of the number of parameters that need to be estimated.

The optimal estimates are then computed in what is called the update step:

$$
\begin{gathered}
\hat{\mathbf{x}}_{t}=\hat{\mathbf{x}}_{t \mid t-1}+\mathbf{P}_{t \mid t-1} \mathbf{H}_{t}^{\prime} \mathbf{F}_{t}^{-1} \mathbf{v}_{t} \\
\mathbf{P}_{t}=\mathbf{P}_{t \mid t-1}-\mathbf{P}_{t \mid t-1} \mathbf{H}_{t}^{\prime} \mathbf{F}_{t}^{-1} \mathbf{H}_{t} \mathbf{P}_{t \mid t-1}
\end{gathered}
$$

Note that the above calculations can be performed even if the number of observations varies with time and that the accuracy of the estimation, measured by the variance of the estimation error, increases with the number of observations that are available to update the filter.

The estimation of model parameters $\hat{\boldsymbol{\Psi}}$ is obtained by maximizing the log-likelihood function of innovations:

$$
\log L(\boldsymbol{\Psi})=-\frac{1}{2} \sum_{t} \log \left|\mathbf{F}_{t}\right|-\frac{1}{2} \sum_{t} \boldsymbol{v}_{t}^{\prime} \mathbf{F}_{t}^{-1} \boldsymbol{v}_{t}
$$

where $\boldsymbol{\Psi}$ represents a vector containing unknown parameters.

\section{EMPIRICAL RESULTS}

\section{Data}

The data used in this study consist of all daily light sweet crude oil futures prices traded at NYMEX from January 1992 to December 2004. There are currently 35 contracts traded for different maturities ranging from 1 to 30 months, and 3, 4, 5, 6, and 7 years. However, from 1992 to 1996, the maximum maturity traded at NYMEX was only 4 years. In 1997, new contracts were introduced to include maturities up to 7 years. 


\section{TABLE I}

Average Number of Daily Observations and Maximum Maturity Available of Light Sweet Crude Oil Futures Contracts for Panel A (1992-2001), B (1992-1996), C (1997-2001), and D (2002-2004)

\begin{tabular}{cccc}
\hline & Year & $\begin{array}{c}\text { Average number } \\
\text { of daily observations }\end{array}$ & $\begin{array}{c}\text { Maximum maturity } \\
\text { (years) }\end{array}$ \\
\hline Panel A & & & \\
Panel B & 1992 & 22 & 3 \\
& 1993 & 22 & 3 \\
& 1994 & 21 & 3 \\
& 1995 & 25 & 4 \\
Panel C & 1996 & 31 & 4 \\
& 1997 & 34 & 7 \\
& 1998 & 31 & 7 \\
& 1999 & 31 & 7 \\
Panel D & 2000 & 33 & 7 \\
& 2001 & 34 & 7 \\
& 2002 & 34 & 7 \\
\hline
\end{tabular}

The data are divided into four different panels in Table I. Panel A includes all futures contracts traded between 1992 and 2001, which correspond to 70,584 observations. In order to analyze the effect (if any) in parameter estimates of the introduction of long-term contracts in 1997, the data are divided into Panel B (1992-1996) and Panel C (1997-2001), with 30,424 and 40,160 observations, respectively. ${ }^{5}$ Panel D is used for out-of-sample testing purposes only, and includes futures traded between 2002 and 2004, with 24,947 observations. Table I presents a description of the data showing the average number of daily observations and the maximum maturity available for each year during the 1992-2004 period.

The time series of the spot oil price from 1992 to 2004 is displayed in Figure 1, where it is possible to appreciate the high volatility exhibited by oil. Spot prices reach a maximum of $\$ 55$ per barrel, and the minimum is as low as $\$ 10$ per barrel. The spot price, defined as the value of an expiring futures contract, is usually unobservable and must be estimated. The simplest way of doing it is to use the closest-to-maturity futures contract as a proxy for the oil spot price. A more rigorous way to estimate the spot price is to set $T=t$ in Equation (17). The price of the closest-tomaturity contract and the theoretical spot price derived from the fourfactor model are similar but not identical, as shown in Figure 1.

${ }^{5}$ The data could also be divided with alternative criteria, like structural breaks in oil prices (Serletis, 1992). 


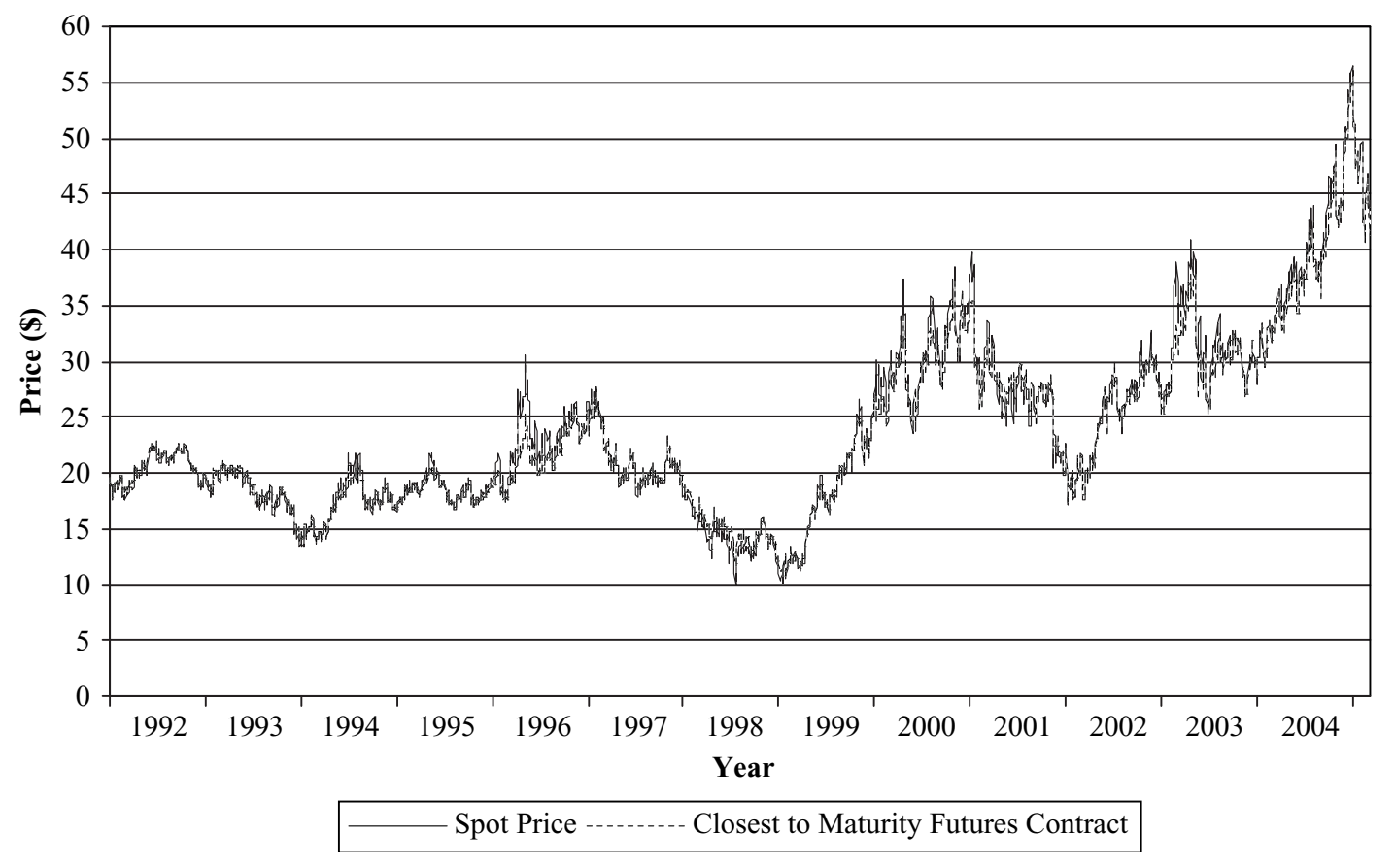

FIGURE 1

Time series of the oil spot price. The figure displays the historic evolution of the theoretical oil spot price, calculated from the four-factor model with the use of parameter estimates from Panel A, and compares it with the closest-to-maturity futures contract from January 1992 to December 2004. The spot price, although very similar, is not identical to the closest-to-maturity futures contract.

\section{Parameter Estimation}

The model is estimated in Table II with the use of one, two, three, and four factors, for three different panels: Panel A from 1992 to 2001, Panel B from 1992 to 1996, and Panel C from 1997 to 2001. The remaining data are used later for robustness tests of the model. The Kalman filter described earlier is used to estimate unobserved state variables, and parameters are obtained by maximizing the likelihood function of futures price innovations.

Parameter estimates are shown in Table II with standard errors in parentheses. From this table it can be seen that most parameters are stable across different panels, which shows the reliability of the model when applied to the oil market. All mean reversion parameters, $\kappa_{i}$, for all three panels, are highly significant and show the existence of strong mean reversion in oil prices. Volatility parameters $\sigma_{i}$ are also highly significant and stable across panels. Correlation parameters $\rho_{i j}$ are almost all significant. As found in the literature (Schwartz, 1997), the long-term growth rate parameter $\mu$ and most risk premium parameters $\lambda_{i}$ are not 


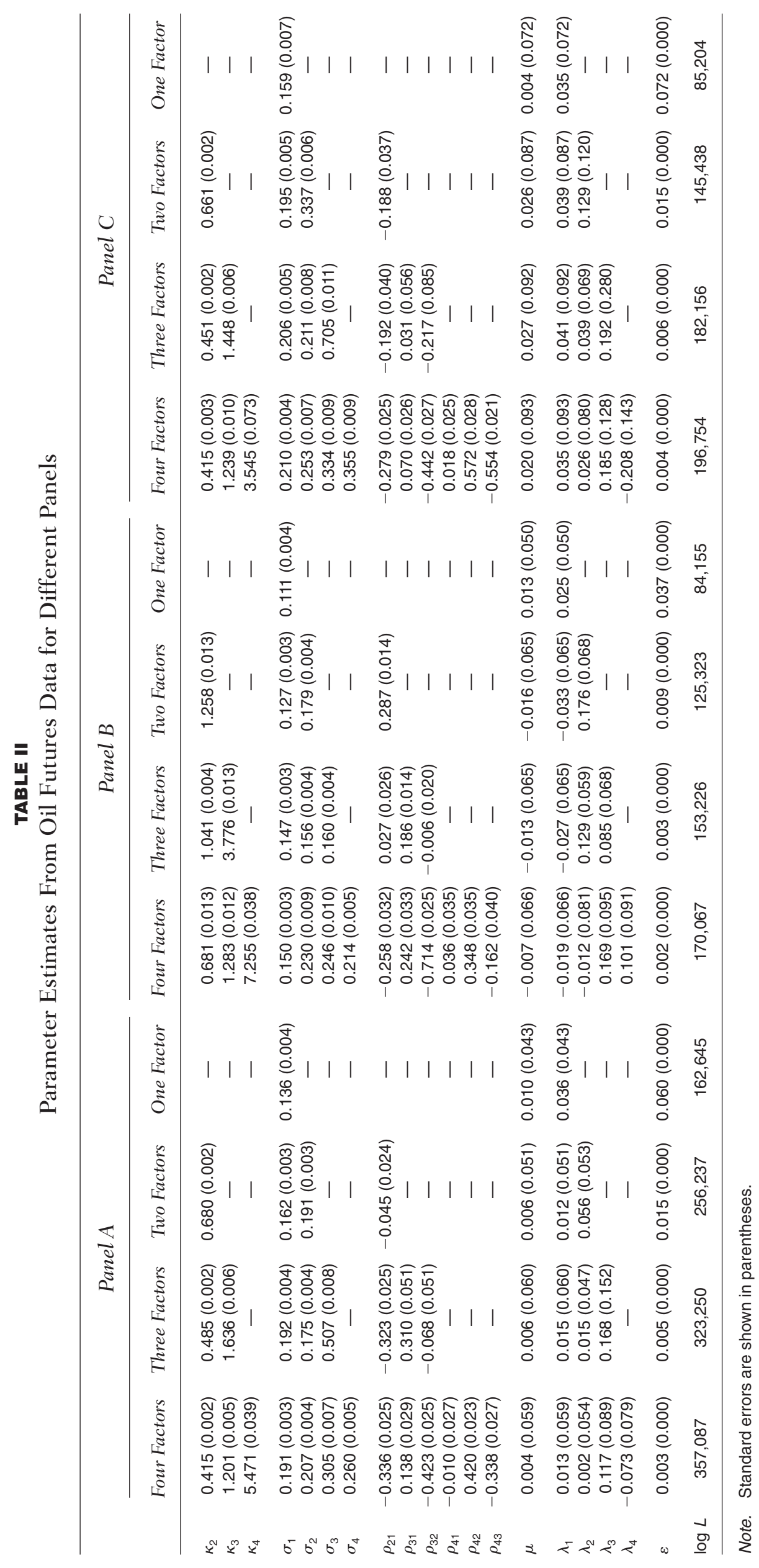




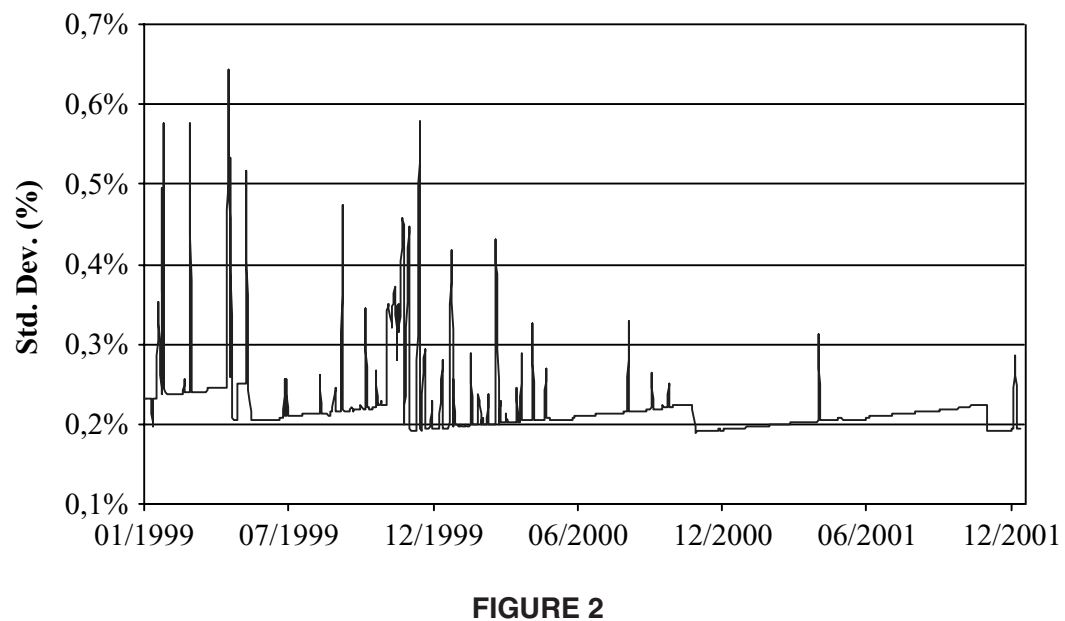

Time series of the standard deviation for state variable $x_{1}$. The figure displays the time evolution from January 1999 to December 2001 of the standard deviation for state variable $x_{1}$ in the four-factor model, which is obtained from the first entry of matrix $\mathbf{P}_{t}$, the covariance matrix of state variable estimation errors.

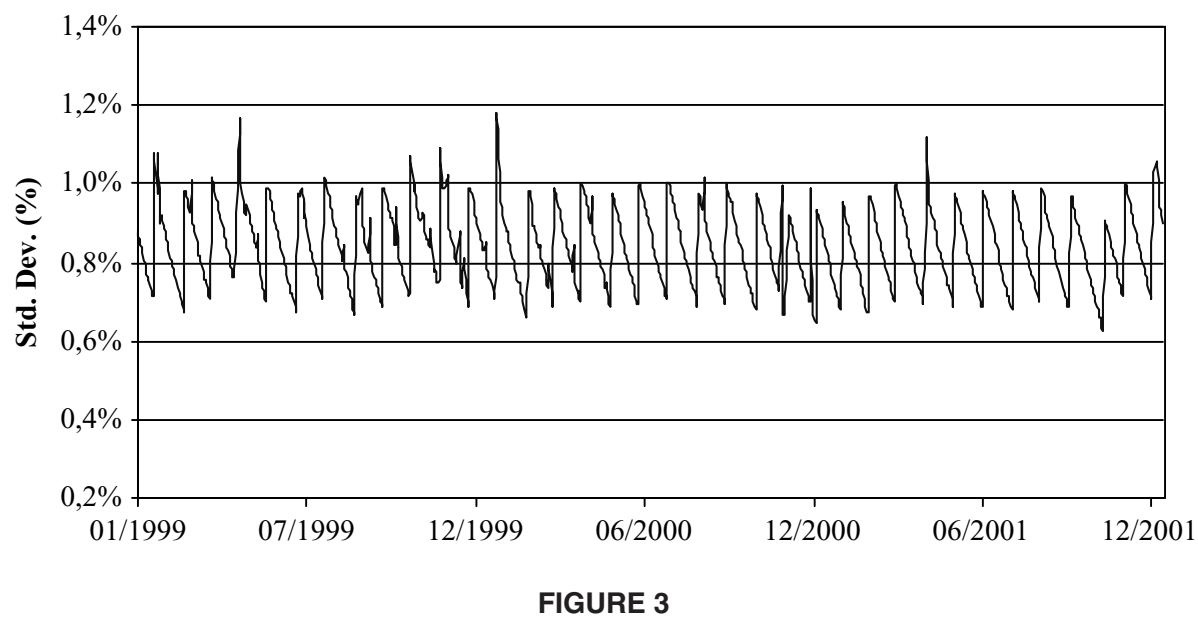

Time series of the standard deviation for state variable $x_{4}$. The figure displays the time evolution from January 1999 to December 2001 of the standard deviation for state variable $x_{4}$ in the four-factor model, which is obtained from the last diagonal entry of matrix $\mathbf{P}_{t}$, the covariance matrix of state variable estimation errors.

statistically significant. The standard deviation measurement error parameter $\xi$ is small, although very significant. ${ }^{6}$

Figures 2 and 3 display the standard deviation of the estimation error, calculated as the squared root of the diagonal elements of matrix $\mathbf{P}_{t}$, for two different state variables in the four-factor model. This is important when incomplete data sets are used. As expected, a more complete data set induces a lower estimation error, but the estimation error of a particular

${ }^{6}$ In this article, this parameter corresponds to the root-mean-squared error (RMSE) for the whole sample. 
state variable should depend on the availability of futures contracts for the specific maturity range represented by that particular state variable.

Figure 2 plots from January 1999 to December 2001 the estimation error of $x_{1}$, which heavily depends on the availability of long-term futures contracts. It can be seen that the estimation error sharply increases for some dates corresponding to days when long-term contracts are not traded. In addition, it shows that the standard deviation increases between two consecutive issues of long-term contracts, because a shorter remaining maturity provides less information of long-term behavior.

Similarly, Figure 3 displays the time evolution from January 1999 to December 2001 of the estimation error for state variable $x_{4}$, which has the highest mean reversion among all state variables. Because short-term futures contracts usually trade every day, there are no abnormal spikes like the ones observed in Figure 2. This standard deviation presents a decreasing seasonal pattern with a 1 -month cycle following monthly emissions of short-term futures contracts.

\section{Model Robustness}

Besides the stability of parameter estimates, the performance of this model and estimation procedure is measured by analyzing the fit to the observed futures prices term structure and the empirical volatility term structure of futures returns.

Figures 4 and 5 show the fit of the models for two dates. These specific dates were chosen as examples of market conditions when oil

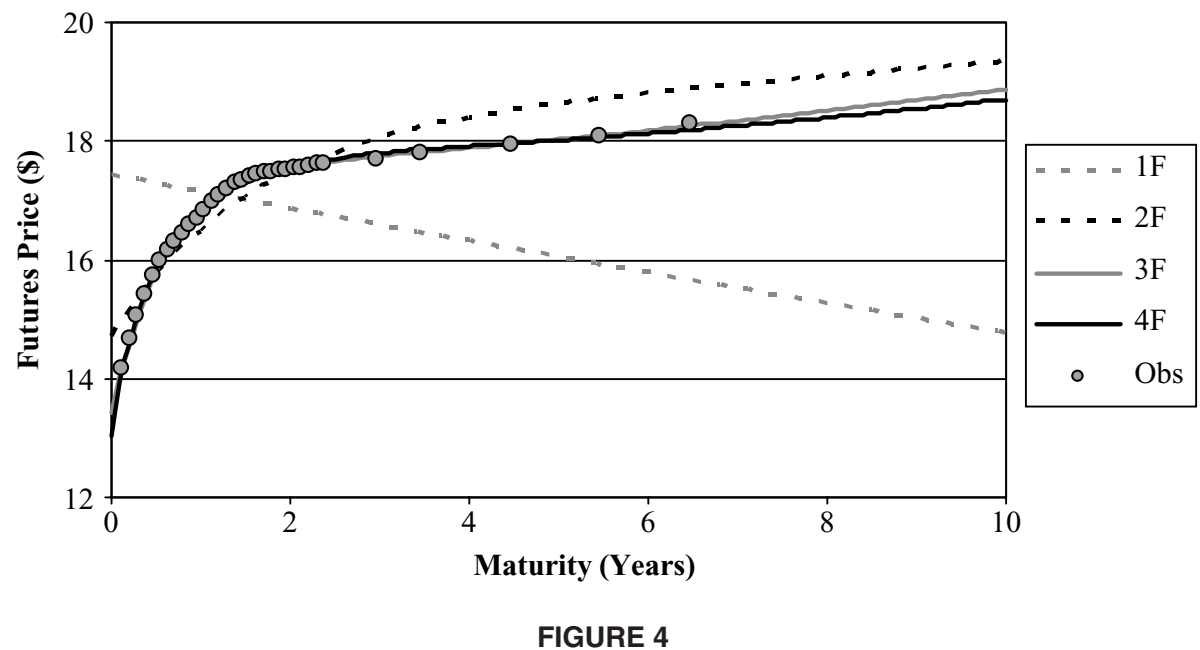

Estimated and observed oil futures prices on 06/30/1998. The figure displays the theoretical term structure of futures prices on 06/30/1998 with the use of one-, two-, three-, and four-factor models, and compares it to observed futures prices when the term structure is in contango. 


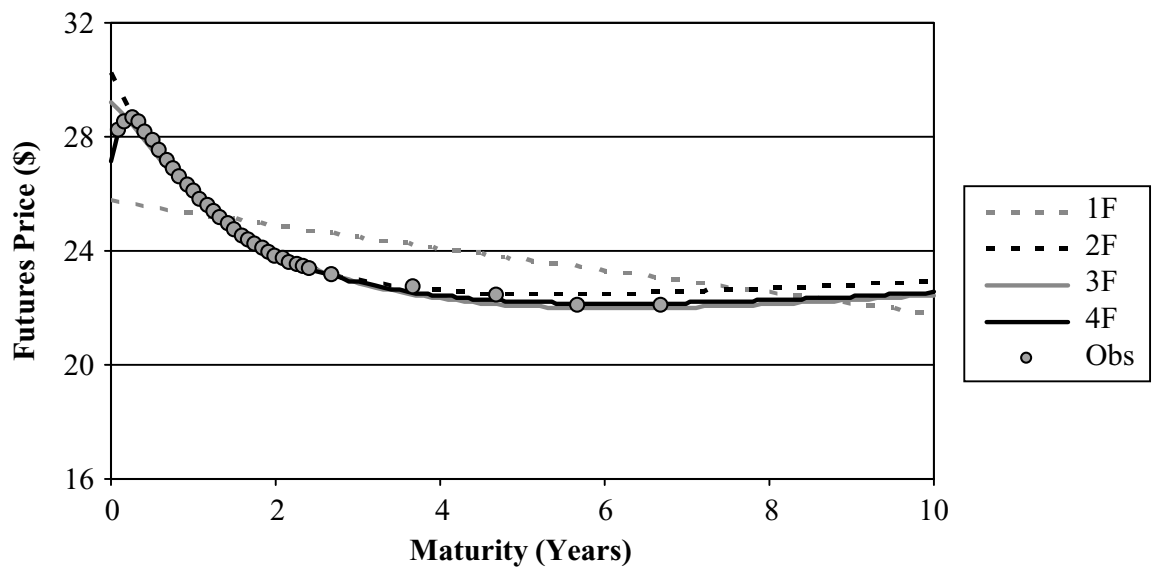

FIGURE 5

Estimated and observed oil futures prices on 04/1 1/2001. The figure displays the theoretical term structure of futures prices on 04/11/2001 with the use of one-, two-, three-, and four-factor models, and compares it to observed futures prices when the term structure is in backwardation.

TABLE III

In-Sample RMSE and Bias for Panels A (1992-2001), B (1992-1996), and C (1997-2001)

\begin{tabular}{lrr}
\hline & RMSE & \multicolumn{1}{c}{ Bias } \\
\hline Panel A & & \\
1F & & \\
2F & $5.92 \%$ & $0.0004 \%$ \\
3F & $1.46 \%$ & $-0.0004 \%$ \\
4F & $0.51 \%$ & $-0.0002 \%$ \\
Panel B & $0.29 \%$ & $-0.0001 \%$ \\
F & & \\
2F & & $-0.0009 \%$ \\
3F & $3.70 \%$ & $0.0000 \%$ \\
4F & $0.87 \%$ & $0.0000 \%$ \\
Panel C & $0.31 \%$ & $0.0000 \%$ \\
1F & $0.16 \%$ & \\
2F & & $0.0010 \%$ \\
3F & & $-0.0003 \%$ \\
$4 \mathrm{~F}$ & $7.12 \%$ & $-0.0003 \%$ \\
\hline
\end{tabular}

futures term structures exhibited strong contango or backwardation. It can be seen that one- and two-factor models cannot fit observed futures prices accurately on these dates, whereas three- and four-factor models fit them very well.

Table III shows the root-mean-squared error (RMSE) and bias of model futures estimates for in-sample data. It can be seen that futures 


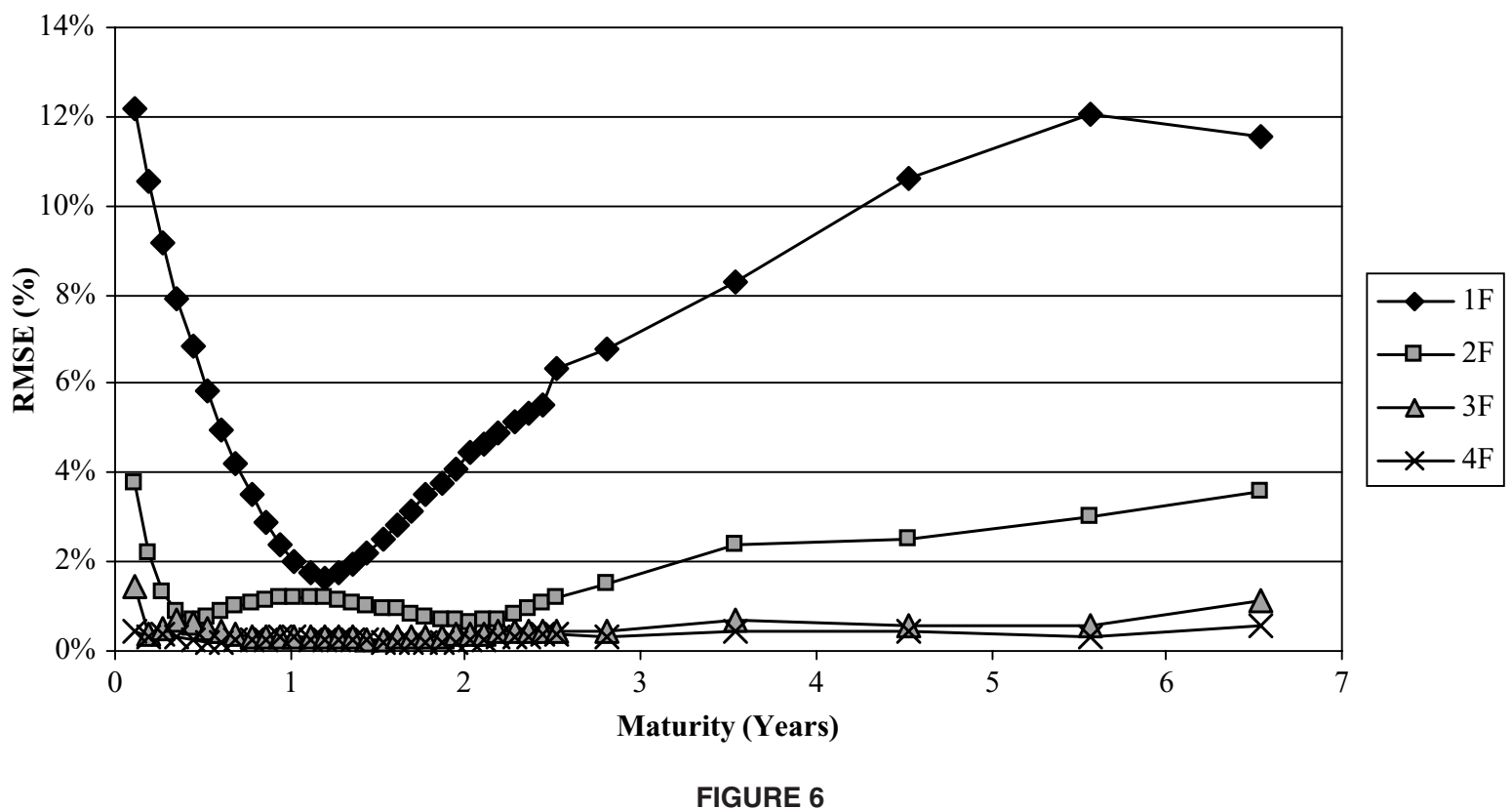

Root-mean-squared errors for each model. The figure is obtained by calculating the in-sample root-mean-squared errors (RMSE) by maturity for the 35 existing oil futures contracts and for each model with the use of Panel A (1992-2001).

price estimations are unbiased for all models and panels and exhibit a RMSE of less than $1 \%$ for three- and four-factor models. For example, in Panel A, considering an average spot oil price of \$21, the RMSE corresponds to an error of only $\$ 0.07$ for the four-factor model. On the other hand, the one-factor model exhibits a high RMSE ranging from 3.70 to $7.12 \%$. Figure 6 displays the RMSE by maturity for each of the models. It can seen that the inclusion of more factors improves the fit for all maturities, especially for short- and long-term contracts.

Another way to measure model stability is to compare the RMSE of out-of-sample and in-sample estimations. For this purpose the RMSE for years 2002, 2003, and 2004 is calculated with the use of Panel A parameters. Table IV displays these results and shows that the RMSE for these years is similar to the RMSE obtained for 2001.

It is important to note that these results are obtained under the assumption that the spot price is nonstationary, which seems reasonable for oil (Schwarz \& Szakmary, 1994). Moreover, Bessembinder et al. (1995) find large and significant mean reversion in agricultural commodities and crude oil futures markets, smaller but statistically significant mean reversion in metals futures, and weak mean reversion in financial futures markets. Thus, one may be concerned that the nonstationarity of the model combined with the embedded assumption of mean 
TABLE IV

In-Sample RMSE for the Year 2001 and Out-of-Sample RMSE for Years 2002-2004 Calculated with Panel A (1992-2001)

Parameters for Different Number of Factors

\begin{tabular}{lllll}
\hline & $2001($ In sample $)$ & 2002 & 2003 & 2004 \\
\hline $1 \mathrm{~F}$ & $5.43 \%$ & $4.38 \%$ & $5.93 \%$ & $5.52 \%$ \\
$2 \mathrm{~F}$ & $1.38 \%$ & $1.22 \%$ & $1.88 \%$ & $1.35 \%$ \\
$3 \mathrm{~F}$ & $0.60 \%$ & $0.66 \%$ & $0.71 \%$ & $0.54 \%$ \\
$4 \mathrm{~F}$ & $0.36 \%$ & $0.53 \%$ & $0.46 \%$ & $0.37 \%$ \\
\hline
\end{tabular}

TABLE V

In-Sample RMSE for the Year 2001 and Out-of-Sample RMSE for Years 2002 to 2004 for Copper Futures With the Use of Different Numbers of Factors

\begin{tabular}{lcccc}
\hline & $2001($ In sample $)$ & 2002 & 2003 & 2004 \\
\hline $1 F$ & $2.46 \%$ & $2.36 \%$ & $1.37 \%$ & $5.88 \%$ \\
$2 \mathrm{~F}$ & $0.25 \%$ & $0.12 \%$ & $0.17 \%$ & $1.29 \%$ \\
$3 \mathrm{~F}$ & $0.16 \%$ & $0.07 \%$ & $0.08 \%$ & $0.44 \%$
\end{tabular}

reversion may make the model fit the oil futures well, but not other commodity futures, like metals. ${ }^{7}$

To address this issue, Table $\mathrm{V}$ presents results for the same model estimated with the use of copper futures for 1, 2, and 3 factors. In particular, the data used in this estimation consist of daily copper futures traded at NYMEX from January 1992 to December 2001. The table displays out-of-sample RMSE for the years 2002, 2003, and 2004, and also in-sample RMSE for the year 2001. It can be seen that results similar to those obtained for oil are found for copper, suggesting that the model behaves well for some metals. This is also consistent with the results reported by Schwartz (1997).

As a last measure of robustness, the model volatility term structure of futures returns is calculated from Equation (18), and compared to the empirical volatilities $\hat{\sigma}_{F}^{2}(\tau)$ obtained directly from observed futures prices:

$$
\hat{\sigma}_{F}^{2}(\tau)=\frac{1}{\Delta t} \sum_{i=1}^{N}\left(\log \left(F\left(t_{i}, \tau\right) / F\left(t_{i}-\Delta t, \tau\right)\right)-\bar{\mu}\right)^{2}
$$

Figure 7 shows, for each model and panel, the theoretical and empirical volatility term structures. It can be seen that one- and twofactor models do not fit the empirical volatility term structure well. Although the volatility term structure in Panel B (1992-1996) fits the

${ }^{7}$ The authors thank the referee for this comment. 

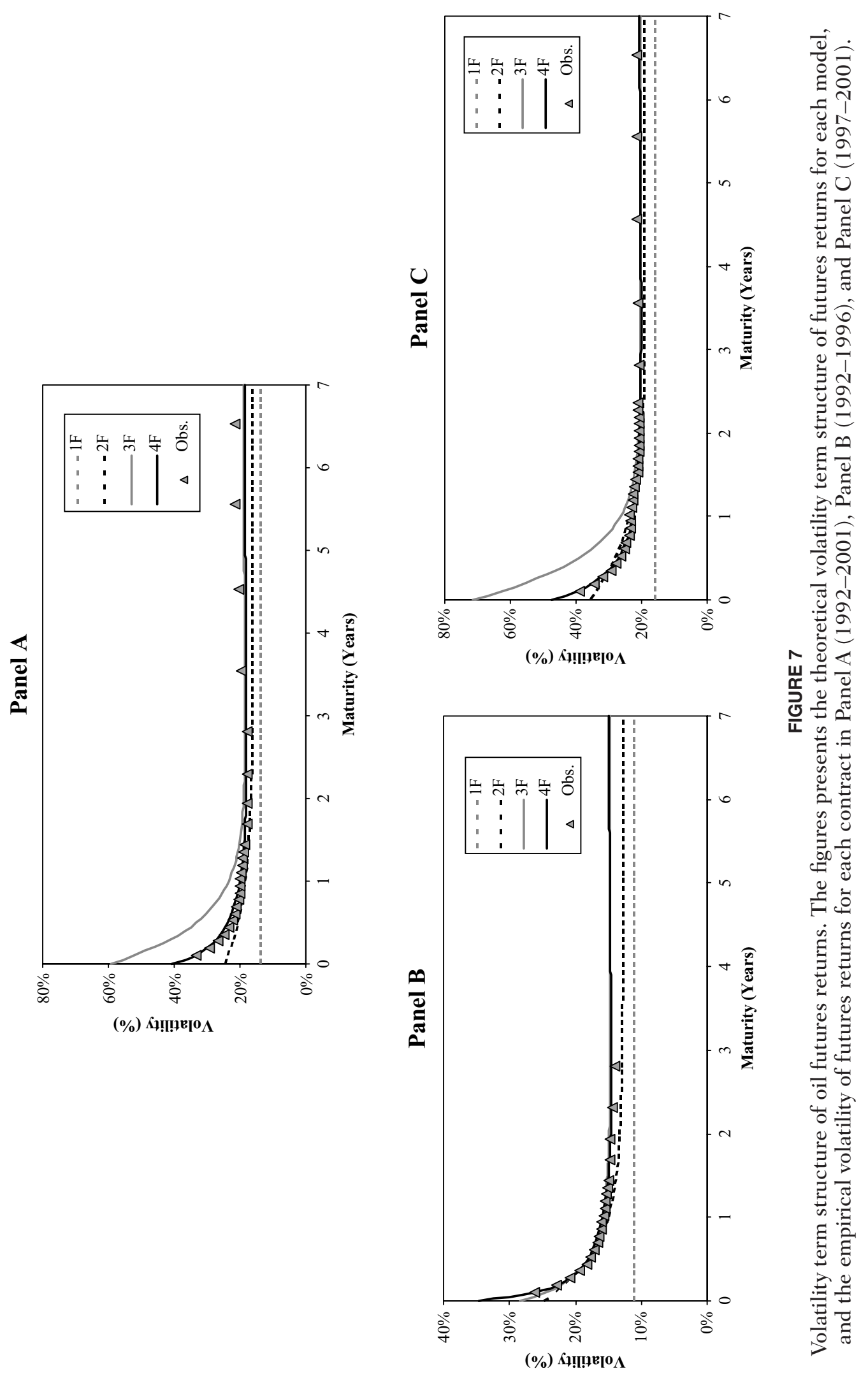
three-factor model very well, it does not perform well in Panel C (1997-2001), as it overestimates the short-term volatility. This translates into an overestimated short-term volatility for Panel A, as it is the union of Panels B and C. On the contrary, the four-factor model closely fits the empirical volatility term structure across all panels.

A possible explanation for the failure of the three-factor model to fit the volatility term structure might be a structural break in the volatility of oil futures returns during the 1992-2001 period. ${ }^{8}$ One way to test this hypothesis is to compare model estimates between the two different periods 1992-1996 and 1997-2001. This could easily be done by comparing the likelihood functions, and seeing whether this difference is significant. One may be concerned, however, that because the current estimation procedure uses a very large number of data points, it will reject any hypothesis of no structural change. On the other hand, it may be interesting to use as much information as possible from the whole futures term structure in testing for structural change.

The structural break is tested by comparing the time-series covariance matrix of state variables for each sample, and then computing a Wald test statistic. In particular, the Wald statistic is computed with the use of the GMM procedure applied to the time-series dynamics of each state variable, and carried out for each model. This generates Waldstatistic values of 456.05, 171.70, 115.19, and 97.51 for the four-, three-, two-, and one-factor models, respectively. Given that critical values at $95 \%$ for this test are 18.31, 12.59, 7.81, and 3.84, respectively, the null hypothesis of no structural change is clearly rejected.

In addition, the presence of volatility parameters in the valuation formula of futures prices might also cause empirical and theoretical volatility term structures to diverge. Because the estimation is performed by improving the likelihood function of price innovations, there is always a trade-off between improving the pricing of futures contracts and the time-series volatility estimation. A larger number of factors gives more flexibility to adjust first and second moments simultaneously, hence explaining why the four-factor model outperforms the three-factor one in fitting the volatility term structure.

\section{CONCLUSIONS}

This article studies the ability of an $\mathrm{N}$-factor Gaussian model to explain the stochastic behavior of oil futures prices when estimated with the use of all available price information. In recent years, oil futures markets

${ }^{8}$ The authors thank the referee for pointing this out. 
have included new futures contracts with longer maturities that do not have historical prices. In addition, not all futures contracts trade every day. To include all data without discarding or aggregating prices, a Kalman filter estimation procedure that allows for a time-dependent number of observations is used.

The model is calibrated with the use of all daily light sweet crude oil futures prices traded at NYMEX during the 10-year period from January 1992 to December 2001. The model is estimated with the use of one, two, three and four factors, for the three different panels: from 1992 to 2001, from 1992 to 1996, and from 1997 to 2001. It is found that most parameter estimates are significant and stable across different panels, as opposed to the long-term growth rate and most risk premium parameters, which are not. Moreover, out-of-sample errors for the 2002-2004 period are similar to in-sample errors, supporting the stability of the model. In addition, the model also performs well for copper futures.

Empirical results show that one and two-factor models fail to accurately fit observed prices and the volatility term structure. The three-factor model, while explaining market prices very well, overestimates the shortterm volatility in some panels, which may be attributed to a structural change in oil prices occurring after 1997. Finally, the four-factor model performs well, explaining the stochastic behavior of oil prices.

In general, the model works well in estimating the term structure of oil futures prices and the volatility term structure of oil futures returns. As such, the model could be useful for oil producers and consumers, and also financial intermediaries like futures traders, in valuing and hedging oil contingent claims. For example, the model could be used to value oillinked financial contracts with option-like characteristics, or to implement long-term hedging strategies with existing futures contracts.

\section{APPENDIX A}

This Appendix deduces Equation (17) with the use of Equation (16). Because the conditional distribution for the spot price $S_{T}$ is lognormal, it follows that

$$
\mathrm{E}_{t}^{Q}\left(S_{T}\right)=\exp \left(\mathrm{E}_{t}^{Q}\left(Y_{T}\right)+\frac{1}{2} \mathrm{~V}_{t}^{Q}\left(Y_{T}\right)\right)
$$

where $Y_{T}=\log \left(S_{T}\right), \mathrm{E}_{t}\left(Y_{T}\right)=\left(\mathbf{1}^{\prime}\right)\left(\mathbf{E}_{t}^{Q}\left(\mathbf{x}_{T}\right)\right)+\mu T$ and $\operatorname{Var}_{t}\left(Y_{T}\right)=\left(\mathbf{1}^{\prime}\right) \times$ $\left(\operatorname{Cov}_{t}^{Q}\left(\mathbf{x}_{T}\right)\right)(\mathbf{1})$. 
From Equation (3) the conditional moments of $\mathbf{x}_{t}$ are

$$
\begin{aligned}
& \mathbf{E}_{t}\left(\mathbf{x}_{T}\right)=\mathrm{e}^{-\mathbf{K}(T-t)} \mathbf{x}_{t}-\left(\int_{0}^{T-t} \mathrm{e}^{-\mathbf{K} \tau} d \tau\right) \boldsymbol{\lambda} \\
& \operatorname{Cov}_{t}\left(\mathbf{x}_{T}\right)=\int_{0}^{T-t} \mathrm{e}^{-\mathbf{K} \tau} \boldsymbol{\Sigma} \boldsymbol{\Theta} \boldsymbol{\Sigma}^{\prime}\left(\mathrm{e}^{-\mathbf{K} \tau}\right)^{\prime} d \tau
\end{aligned}
$$

where $\boldsymbol{\Theta} d t=\left(d \mathbf{w}_{t}\right)\left(d \mathbf{w}_{t}\right)^{\prime}$. Thus

$$
\begin{gathered}
\mathrm{E}_{t}^{Q}\left(x_{i}(T)\right)=\left\{\begin{array}{cl}
x_{1}(t)-\lambda_{1}(T-t) & i=1 \\
\mathrm{e}^{-\kappa_{i}(T-t)} x_{i}(t)-\frac{1-\mathrm{e}^{-\kappa_{i}(T-t)}}{\kappa_{i}} \lambda_{i} & i=2, \ldots, N
\end{array}\right. \\
\operatorname{Cov}_{t}^{Q}\left(x_{i}(T), x_{j}(T)\right)=\left\{\begin{array}{cc}
\sigma_{1}^{2}(T-t) & i=1, j=1 \\
\sigma_{i} \sigma_{j} \rho_{i j} \frac{1-e^{-\left(\kappa_{i}+\kappa_{j}\right)(T-t)}}{\kappa_{i}+\kappa_{j}} & i \neq 1, j \neq 1
\end{array}\right.
\end{gathered}
$$

The valuation formula (17) is obtained by inserting Equations (33) and (34) into Equation (30).

\section{BIBLIOGRAPHY}

Babbs, S. H., \& Nowman, K. B. (1999). Kalman filtering of generalized Vasicek term structure models. Journal of Financial and Quantitative Analysis, 34, $115-130$.

Bessembinder, H., Coughenour, J. F., Seguin, P. J., \& Smoller, M. M. (1995). Mean reversion in equilibrium asset prices: Evidence from the futures term structure. Journal of Finance, 50, 361-375.

Bessembinder, H., Coughenour, J. F., Seguin, P. J., \& Smoller, M. M. (1996). Is there a term structure of futures volatilities? Reevaluating the Samuelson hypothesis. Journal of Derivatives, 4, 45-58.

Brennan, M. J. (1958). The supply of storage. American Economic Review, 48, $50-72$.

Brennan, M. J. (1991). The price of convenience and the valuation of commodity contingent claims. In D. Lund, \& B. Øksendal (Eds.), Stochastic models and option values (pp. 33-71). Amsterdam: Elsevier Science.

Brennan, M. J., \& Schwartz, E. S. (1985). Evaluating natural resources investments. Journal of Business, 58, 135-157.

Casassus, J., \& Collin-Dufresne, P. (2005). Stochastic convenience yield implied from commodity futures and interest rates. Journal of Finance, 60, 2283-2331.

Chen, R. R., \& Scott, L. (1993). Maximum likelihood estimation for a multifactor equilibrium model of the term structure of interest rates. Journal of Fixed Income, 3, 14-31. 
Cortazar, G., \& Schwartz, E. S. (1994). The valuation of commodity-contingent claims. Journal of Derivatives, 1, 27-35.

Cortazar, G., \& Schwartz, E. S. (2003). Implementing a stochastic model for oil futures prices. Energy Economics, 25, 215-238.

Cortazar, G., Schwartz, E. S., \& Naranjo, L. F. (2003). Term structure estimation in low-frequency transaction markets: A Kalman filter approach with incomplete panel-data (working paper). Los Angeles: University of California, Anderson School of Management.

Cox, J. C., Ingersoll, J., \& Ross, S. (1981). The relation between forward prices and futures prices. Journal of Financial Economics, 9, 321-46.

Culp, C. L., \& Miller, M. H. (1994). Hedging a flow of commodity deliveries with futures: Lessons from Metallgesellschaft. Derivatives Quarterly, 1, 7-15.

Dai, Q., \& Singleton, K. J. (2000). Specification analysis of affine term structure models. Journal of Finance, 55, 1943-1978.

de Jong, F. (2000). Time-series and cross-section information in affine term structure models. Journal of Business \& Economics Statistics, 18, 300-314.

de Jong, F., \& Santa-Clara, P. (1999). The dynamics of the forward interest rate curve: A formulation with state variables. Journal of Financial and Quantitative Analysis, 34, 131-157.

Deaton, A., \& Laroque, G. (1992). On the behavior of commodity prices. Review of Economic Studies, 59, 1-23.

Duan, J. C., \& Simonato, J. G. (1999). Estimating and testing exponential-affine term structure models by Kalman filter. Review of Quantitative Finance and Accounting, 13, 111-135.

Duffie, D., \& Singleton, K. J. (1997). An econometric model of the term structure of interest-rate swap yields. Journal of Finance, 52, 1287-1321.

Geyer, A. L. J., \& Pichler, S. (1999). A state-space approach to estimate and test multifactor Cox-Ingersoll-Ross models of the term structure. Journal of Financial Research, 22, 107-130.

Gibson, R., \& Schwartz, E. S. (1990). Stochastic convenience yield and the pricing of oil contingent claims. Journal of Finance, 45, 959-976.

Harvey, A. C. (1989). Forecasting, structural time series models and the Kalman filter. Cambridge: Cambridge University Press.

Heath, D., Jarrow, R., \& Morton, A. (1992). Bond pricing and the term structure of interest rates: A new methodology for contingent claims valuation. Econometrica, 60, 77-105.

Hilliard, J. E., \& Reis, J. (1998). Valuation of commodity futures and options under stochastic convenience yields, interest rates, and jump diffusions in the spot. Journal of Financial and Quantitative Analysis, 33, 61-86.

Langetieg, T. C. (1980). A multivariate model of the term structure. Journal of Finance, 35, 71-97.

Laughton, D. G., \& Jacoby, H. D. (1993). Reversion, timing options, and longterm decision-making. Financial Management, 22, 225-240.

Laughton, D. G., \& Jacoby, H. D. (1995). The effects of reversion on commodity projects of different length. In L. Trigeorgis (Ed.), Real options in capital investments: Models, strategies, and applications (pp. 185-205). Westport, CT: Praeger. 
Lund, J. (1994). Econometric analysis of continuous-time arbitrage-free models of the term structure of interest rates (working paper). Aarhus, Denmark: Aarhus School of Business.

Lund, J. (1997). Non-linear Kalman filtering techniques for term-structure models (working paper). Aarhus, Denmark: Aarhus School of Business.

Manoliu, M., \& Tompaidis, S. (2002). Energy futures prices: Term structure models with Kalman filter estimation. Applied Mathematical Finance, 9, 21-43.

Miltersen, K. R., \& Schwartz, E. S. (1998). Pricing of options on commodity futures with stochastic term structures of convenience yields and interest rates. Journal of Financial and Quantitative Analysis, 33, 33-59.

Pearson, N. D., \& Sun, T. S. (1994). Exploiting the conditional density in estimating the term structure: An application to the Cox, Ingersoll, and Ross model. Journal of Finance, 49, 1279-1304.

Pennacchi, G. G. (1991). Identifying the dynamics of real interest rates and inflation: Evidence using survey data. Review of Financial Studies, 4, 53-86.

Ross, S. A. (1997). Hedging long run commitments: Exercises in incomplete market pricing. Economic Notes by Banca Monte, 26, 99-132.

Routledge, B. R., Seppi, D. J., \& Spatt, C. S. (2000). Equilibrium forward curves for commodities. Journal of Finance, 55, 1297-1339.

Schwartz, E. S. (1997). The stochastic behavior of commodity prices: Implications for valuation and hedging. The Journal of Finance, 52, 923-973.

Schwartz, E. S., \& Smith, J. E. (2000). Short-term variations and long-term dynamics in commodity prices. Management Science, 46, 893-911.

Schwarz, T. V., \& Szakmary, A. C. (1994). Price discovery in petroleum markets: Arbitrage, cointegration, and the time interval of analysis. Journal of Futures Markets, 14, 147-167.

Serletis, A. (1992). Unit root behavior in energy futures prices. Energy Journal, 13, 119-128.

Sørensen, C. (2002). Modeling seasonality in agricultural commodity futures. Journal of Futures Markets, 22, 393-426.

Vasicek, O. (1977). An equilibrium characterization of the term structure. Journal of Financial Economics, 5, 177-188.

Working, H. (1949). The theory of price of storage. American Economic Review, 39, 1254-1262. 